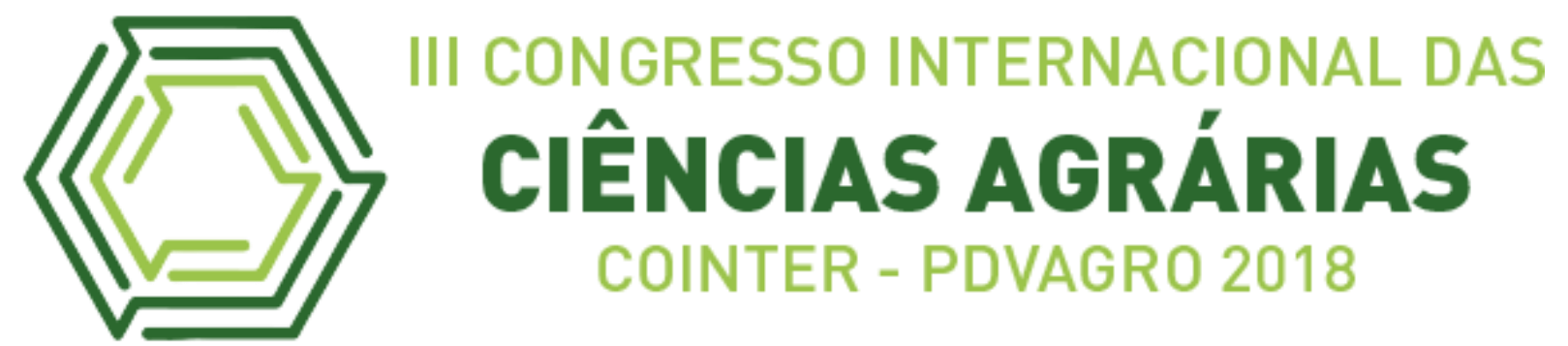

\title{
EDUCAÇÃO AMBIENTAL CRÍTICA NO IFPE- CAMPUS VITÓRIA DE SANTO ANTÃO
}

\section{CRITICAL ENVIRONMENTAL IN IFPE-CAMPUS VITÓRIA DE SANTO ANTÃO}

\author{
Apresentação: Pôster
}

\author{
Renata Andrade Lima ${ }^{1}$; Rivaldo Vieira da Silva Filho ${ }^{2}$; Martha Carolina de Medeiros \\ Cavalcanti ${ }^{3}$; ${ }^{4}$ Maciel Alves Tavares; Rogério Alves de Lima ${ }^{5}$
}

\section{DOI: https://doi.org/10.31692/2526-7701.IIICOINTERPDVAGRO.2018.00437}

\section{Introdução}

Educação Ambiental Crítica (EAC) também conhecida como educação ambiental tradicional, conservadora ou popular, vem sendo tratada como uma alternativa a consolidação de uma educação ambiental mais hegemônica, esta que não expande mudanças significativas às necessidades de modificações da sociedade a qual vivemos.

Segundo Loureiro (2004), a EAC propõe promover o questionamento às abordagens comportamentalistas, reducionistas e dualistas no entendimento da relação cultura-natureza. Além dele, outros pesquisadores, autores e teóricos definem essa educação como uma forma de se reverter a "crise socioambiental". NOVICKI (2004); LUIZ GUIMARÃES (2000, 2007); GRÜN, (1996); LOUREIRO, (2004); LAYRARGUES, (1997). Nota-se então, que essa educação muitas vezes reconhecida como ecopedagógica, surge da educação de Paulo Freire da pedagogia crítica marxista e neomarxista de interpretação da realidade social, associandose a ecologia politica que insere questões ambientais e socioambientais.

O presente trabalho tem como objetivo, a partir das discussões e reflexões, realizar uma mudança comportamental no ambiente escolar do Instituto Federal de Pernambuco Campus Vitória de Santo Antão, uma vez que, trata-se de um campus de origem agrícola e, que os assuntos ambientais devem estar em evidência nas discursões de sala de aula e na prática da comunidade acadêmica para conservação do meio ambiente.

\footnotetext{
${ }^{1}$ Engenharia Agronômica, IFPE- Campus Vitória, renataprisco1@gmail.com

2 Engenharia Agronômica, IFPE- Campus Vitória, rivaldomapeli@gmail.com

${ }^{3}$ Engenharia Agronômica, IFPE- Campus Vitória, marthamedeiroscavalcanti@gmail.com

${ }^{4}$ Engenharia Agronômica, IFPE- Campus Vitória, macieltavares15@gmail.com

${ }^{5}$ Professor Mestre em Sociologia, UFPE, rogerio.lima@vitoria.ifpe.edu.br
} 


\section{Fundamentação Teórica}

Karl Marx em sua obra Manuscrito Econômico e Filosóficos de 1844 define o seguinte, "A natureza é um corpo inorgânico do homem. O homem vive da natureza, ou também, a natureza é o seu corpo, com qual tem de manter-se em permanente intercâmbio para não morrer.

Ainda segundo Marx (1884), afirmar que a vida física e espiritual do homem e a natureza são interdependentes significa apenas que a natureza se inter-relaciona consigo mesma, já que o homem é uma parte da natureza. Assim, apresenta-se a atividade humana como transformadora, exercendo mudanças sobre a matéria, resultando a produção/conservação de um bem que tem um valor de uso social/educativo.

Ao analisar as contribuições das teorias críticas à EA, ressalta que, em um sentido particular à teoria educacional, pode-se considerar como crítica a todas as pedagogias divergentes da prática educativa tradicional marcada por [...] uma organização curricular fragmentada e hierarquizada, neutralidade do conhecimento transmitido e produzido; e organização escolar e planejamento do processo de ensino e aprendizagem concebidos como pura racionalidade, pautados em finalidades pedagógicas desinteressadas quanto às implicações sociais de suas práticas (LOUREIRO, 2006).

Nesse sentido, demonstra-se a necessidade de atenção à educação ambiental, abordada por meio de uma educação popular, mediante a reflexões pedagógicas e politicas de nomes como Paulo Freire, Gadotti e Torres (1994) que definem a educação popular como uma alternativa político-pedagógica aos projetos educativos tradicionais dominantes, que se constituem simultaneamente como modelo teórico e como prática social.

Sendo analisada através de uma perspectiva para a transformação da sociedade, a EAC apresenta-se com maior "força", pois tende a analisar problemas socioambientais com maior ênfase, sendo encontradas predominantemente em práticas ofertadas em escolas, unidades de conservação e até em comunidades. Em 1999 foi outorgada a Política Nacional de Educação Ambiental, a qual expõe no Art. $2^{\circ}$ "A educação ambiental é um componente essencial e permanente da educação nacional, devendo estar presente, de uma forma articulada, em todos os níveis e modalidades do processo educativo, em caráter formal e não formal.”.

Visto isso, tendo um ambiente totalmente agrícola, o envolvimento com o meio torna- 
se mais intensificado, a partir das praticas que são efetuadas no Campus, é preciso conscientizar o seu manejo e preservação, sendo a partir de uma percepção ambiental ou até mesmo por uma EAC, que objetiva promover ambientes educativos e de mobilização, visando uma redefinição das relações seres humanos-natureza, considerando assim, inserir um processo educativo a essa EAC a partir de uma analise de ferramenta de pesquisa, visando à construção de um conhecimento e pratica sobre tal, afim de promover uma interação entre ser humano e o meio-ambiente, formulando a formação da cidadania, na expectativa do exercício de um movimento coletivo conjunto, gerador de mobilização para a construção de uma nova sociedade ambientalmente sustentável.

\section{Metodologia}

O presente trabalho será dividido em duas etapas. Na primeira etapa será realizada aplicação do questionário sobre o conhecimento educativo crítico ambiental com os estudantes dos cursos técnicos, de agropecuária e agroindústria, integrados ao ensino médio, do Instituto Federal de Pernambuco - Campus Vitória de Santo Antão.

$\mathrm{Na}$ segunda etapa realizaremos análise dos questionários, onde observaremos o conhecimento destes sobre as problemáticas ambientais e, por fim iremos propor discussões e reflexões nas salas de aula para mudança comportamental dos estudantes perante a comunidade acadêmica.

\section{Resultados e Discussões}

O trabalho teve como pauta inicial observar o nível de conhecimento dos alunos integrados ao meio ambiente do campus como forma de inseri-los ao meio, criando medidas de conservação e um olhar mais sócio educativo para o mesmo, após os resultados observamos a falta de conhecimento diante das perguntas abordadas, onde $75 \%$ dos entrevistados diziam-se sentir-se integrados ao Campus, porém não sabiam o que significava uma educação ambiental crítica e muito menos que o Instituto os instrui para tal medida conservadora, trazendo a real necessidade de abordar-se tal assunto em sala de aula, entretanto os outros $25 \%$ diziam que não causam degradação ao meio, porém assim como a parcela maior, via a necessidade de se ter uma cultura de preservação no Campus, e orientação (conhecimento) educacional para tal prática.

Apresentou-se ainda um percentual de $100 \%$ dos estudantes dos cursos de agropecuária e agroindústria, que evidenciaram, sentir-se integrados ao meio, enfatizando que a partir do momento em que o ser humano se sente como elemento integrante do meio 
ambiente, é capaz de amenizar problemas ambientais, conservar, preservar e atribuir valores educacionais na formação de indivíduos mais críticos a preservação da natureza.

Gráfico 1: Números de homens X Números de mulheres. (Entrevistado(as)). Fonte: Própria

\section{$\mathbf{N}^{\circ}$ de entrevistados}

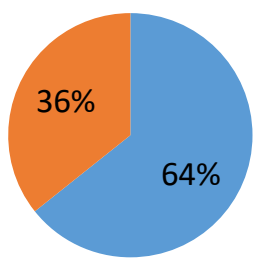

$1^{\circ}$ Masculino

$2^{\circ}$ Feminino

Gráfico 2: Entrevistados X Percentual de idade. Fonte: Própria

\section{Faixa etária sexo masculino}

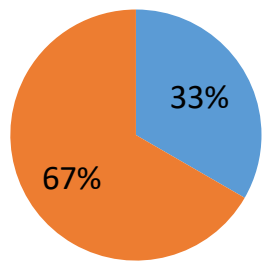

1015 anos

20 16/17 anos

Gráfico 3: Mulheres entrevistadas X Percentual de idade. Fonte: Própria

\section{Faixa etária sexo feminino}

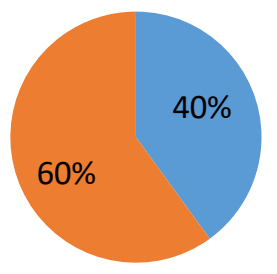

1015 anos

20 16/17 anos

\section{Conclusões}

A partir das observações realizadas, pudemos concluir que a Educação Ambiental Crítica deve ser parte integrante da comunidade escolar, reforçando as reflexões e as ações perante o meio ambiente.

Cada estudante envolvido é uma parcela para essa mudança socioambiental no Campus Vitória de Santo Antão, PE refletindo assim, o principio da pesquisa, que diante de 
uma comunidade escolar agrícola o manejo consciente do ambiente é essencial para sua preservação e construção de uma nova cultura de conservação, induzindo e promovendo o aprendizado de novas atitudes e valores em relação a esse meio, viabilizando uma nova dinâmica ambiental.

Diante disso, podemos observar que as maiorias dos alunos não tinham noção da real necessidade de se conservar o meio ambiente, pois a partir da leitura dos questionários, notouse a deficiência educacional sobre o tema abordado em sala, evidenciando a necessidade de se construir uma educação crítica ambiental no campus.

\section{Referências}

FREIRE, P. Pedagogia da Autonomia $2^{\circ}$ ed. Revista. Rio de Janeiro: Paz e Terra, 1997.

GUSTAVO F. C. LIMA. Artigo. Educação ambiental crítica: do socioambientalismo às sociedades sustentáveis

GUIMARÃES, M. A. Artigo. Caminhos da educação ambiental da formação. $3^{\circ}$ ed. Campinas: Papirus, 2008. p. 51-86.

GUIMARÃES, R. A ética da sustentabilidade e a formulação de políticas de desenvolvimento. In: VIANA, G. et al. (Org.)

O desafio da sustentabilidade São Paulo: Fundação Perseu Abramo, 2001.

GRÜN, M. Ética e Educação Ambiental : A conexão necessária. Revista. $3^{a}$ ed. São Paulo: Papirus, 1996.

LAYRARGUES, P. P. "A resolução de problemas ambientais locais deve ser um temagerador ou a atividade-fim da Educação Ambiental". In: REIGOTA, M. (Org.). Verde cotidiano: o meio ambiente em discussão. Revista. Rio de Janeiro: DP\&A, pp. 131-148, 1999.

LOUREIRO , Carlos Frederico B. (Org.). Artigo. A questão ambiental no pensamento crítico: natureza, trabalho e educação . Rio de Janeiro: Quartet, 2007

MARX, Karl. Obra. Manuscritos econômicos e filosóficos. São Paulo: Boitempo, 2010.

MEIRA, P. Elogio da educação ambiental: da década da educação ambiental para o desenvolvimento sustentável ao milênio da educação ambiental. In: Jornadas Pedagógicas da Educação Ambiental: Educação ambiental no contexto da década das Nações

Unidas da educação para o desenvolvimento sustentável (2005-2014). 12., Ericeira, Anais. 2005 p. 14-18. (Conferência)

NOVICKI, V. Artigo. Práxis: problematizando consciência e participação na educação ambiental brasileira. 
